\title{
Zinc finger proteins: insights into the transcriptional and post transcriptional regulation of immune response
}

\author{
Gurseen Rakhra ${ }^{1}$. Gurmeen Rakhra ${ }^{2}$ \\ Received: 25 April 2021 / Accepted: 8 July 2021 / Published online: 24 July 2021 \\ (c) The Author(s), under exclusive licence to Springer Nature B.V. 2021
}

\begin{abstract}
Background Zinc finger proteins encompass one of the unique and large families of proteins with diversified biological functions in the human body. These proteins are primarily considered to be DNA binding transcription factors; however, owing to the diverse array of zinc-finger domains, they are able to interact with molecules other than DNA like RNA, proteins, lipids and PAR (poly-ADP-ribose). Evidences from recent scientific studies have provided an insight into the potential functions of zinc finger proteins in immune system regulation both at the transcriptional and post transcriptional level. However, the mechanism and importance of zinc finger proteins in the regulation of immune response is not very well defined and understood. This review highlights in detail the importance of zinc finger proteins in the regulation of immune system at transcriptional and post transcriptional level.

Conclusion Different types of zinc finger proteins are involved in immune system regulation and their mechanism of regulation is discussed herewith.
\end{abstract}

Keywords Interleukins $\cdot$ Macrophages $\cdot$ mRNA degradation $\cdot$ Transcription factors $\cdot$ Tumor Necrosis factor (TNF) Zinc finger proteins

$\begin{array}{ll}\text { Abbreviations } \\ \text { ZFPs } & \text { Zinc finger proteins } \\ \text { Blimp1 } & \text { B lymphocyte-induced maturation protein } \\ & 1 \\ \text { BCL1 } & \text { B cell lymphoma-1 } \\ \text { EBF } & \text { Early B-cell factors } \\ \text { ZNF521 } & \text { Zinc finger protein 521 } \\ \text { LRF } & \text { Leukemia/lymphoma-related factor } \\ \text { Zbtb1 } & \text { Zinc finger and BTB domain containing 1 } \\ \text { CLP } & \text { Common lymphoid progenitor } \\ \text { KRAB-ZFPs } & \begin{array}{l}\text { Kruppel-associated box domain Zinc fin- } \\ \text { ger proteins }\end{array} \\ \text { KSHV } & \text { Kaposi's sarcoma-associated herpes virus } \\ \text { MCPIP1 } & \begin{array}{l}\text { Monocyte chemotactic protein-induced } \\ \text { protein 1 }\end{array}\end{array}$

Gurmeen Rakhra

gurmeen.25169@1pu.co.in

1 Department of Nutrition \& Dietetics, Faculty of Allied Health Sciences, Manav Rachna International Institute of Research \& Studies, Faridabad, Haryana 121004, India

2 Department of Biochemistry, School of Bioengineering and Biosciences, Lovely Professional University, Phagwara, India

$\begin{array}{ll}\text { ARE } & \text { AU rich elements } \\ \text { TNF } & \text { Tumor Necrosis factor } \\ \text { TTP } & \text { Tristetraprolin } \\ \text { DP } & \text { Constitutive Decay Element } \\ \text { PRRs } & \text { Pattern recognition receptors } \\ \text { LPS } & \text { Lipopolysachharide }\end{array}$

\section{Background}

Zinc plays an important role in different aspects of human health (clinical as well as epidemiological) in public health practices. Zinc is an essential nutrient which serves as a cofactor to many enzymes involved in the metabolism of various biomolecules including proteins, carbohydrates, nucleic acids and lipids. It is known to play a key role in the immune system, affecting both cellular and humoral immunity [1].The essentiality of $\mathrm{Zn}$ was first of all established in the mid-nineteenth century by the French physiologist, Raulin when it was observed that this element was mandatory for the growth of bread mould (Aspergillus niger).

The $\mathrm{Zn}$ chemistry principally is centered in its involvement in the function of a diverse set of proteins which includes different metalloenzymes/metalloproteins in 
addition to nuclear transcription factors. One of the important classes of zinc proteins is zinc finger proteins (ZFPs), which were first discovered in the cell nucleus of a frog, Xenopus laevis [2]. Zinc ions complexed with cysteine and histidine amino acid residues forms Cys2His2 zinc finger motifs, thereby conferring a native tertiary configuration to the protein, hence the name. Later on, it was found that several negatively charged amino acids combining in various ways (e.g. Cys2His2, Cys4, Cys6, etc.) were also found in zinc finger proteins [3]. The different types of zinc finger proteins are listed in Table 1.

The in-depth characterization of Zinc finger proteins has implicated them in several functions. Zinc finger proteins are basically thought of as transcription factors meant primarily to bind DNA. However, some of the zinc finger proteins and related zinc binding motifs are also known to bind to RNA [4], lipids [5] and some of the other proteins [6]. These proteins serve diverse biological functions in human body, such as in development and differentiation processes, metabolism, transcriptional as well as post transcriptional regulation and activation, protein degradation and signal transduction etc. In fact, the diverse combinations and functions of these zinc finger proteins have made these proteins versatile in biological system.

\section{Involvement of zinc finger proteins in immune system}

The immune response is regulated at both the transcriptional as well as the post transcriptional level. Zinc finger proteins have important role to play in the control and

Table 1 Different types of zinc finger proteins in biological system

\begin{tabular}{|c|c|c|}
\hline Type of Zinc finger protein & Structure & Examples \\
\hline 1. Zinc fingers $\mathrm{C} 2 \mathrm{H} 2$-type(ZNF) & $\mathrm{C}-\mathrm{x}-\mathrm{C}-\mathrm{x}-\mathrm{H}-\mathrm{x}-\mathrm{H}$ & $\begin{array}{l}\text { KLF4,KLF5,EGR3,ZFP637,SLUG,ZNF750, } \\
\text { ZNF281,ZBP89,GLIS1,GLIS3 }\end{array}$ \\
\hline 2. LIM domain containing & C-x-C-x-H-x-C-x-C-x-C-x-C-x-(C,H,D) & ZNF185,LIMK1,PXN \\
\hline 3. PHD finger proteins(PHF) & C-x-C-x-C-x-C-xxx-H-x-C-x-C-x-C & KDM2A,PHF1,ING1 \\
\hline 4. Ring finger proteins(RNF) & C-x-C-x-C-x-H-xxx-C-x-C-x-C-x-C & MDM2,BRCA1,ZNF179 \\
\hline 5. Nuclear hormone receptors(NR) & C-x-C-x-C-x-C-xxx-C-x-C-x-C-x-C & VDR,ESR1,NR4A1 \\
\hline 6. Zinc fingers $\mathrm{CCCH}$-type( $\mathrm{ZC} 3 \mathrm{H})$ & $\mathrm{C}-\mathrm{x}-\mathrm{C}-\mathrm{x}-\mathrm{C}-\mathrm{x}-\mathrm{H}$ & RC3H1,HELZ,MBNL1,ZFP36,ZFP36L1 \\
\hline 7. Zinc fingers CCHC- type(ZCCHC) & $\mathrm{C}-\mathrm{x}-\mathrm{C}-\mathrm{x}-\mathrm{H}-\mathrm{x}-\mathrm{C}$ & CNBP,SF1,LIN28A \\
\hline 8. Zinc fingers FYVE-type(ZFYVE) & $C-x-C-x-C-x-C-x x x-C-x-C-x-C-x-C$ & EEA1,HGS,PIKFYVE \\
\hline 9. Zinc fingers DHHC-type(ZDHHC) & C-x-C-x-H-x-C-xxx-C-x-C-x-H-x-C & ZDHHC2,ZDHHC8,ZDHHC9 \\
\hline 10. Zinc fingers MYND-type(ZMYND) & C-x-C-x-C-x-C-xxx-C-x-C-x-H-x-C & PDCD2,RUNX1T1,SMYD2,SMYD1 \\
\hline 11. Zinc fingers RANBP2-type(ZRANB & $C-x-C-x-C-x-C$ & YAF2,SHARPIN,EWSR1 \\
\hline 12. Zinc fingers ZZ-type(ZZZ) & $C-x-C-x-C-x-C$ & HERC2,NBR1,CREBBP \\
\hline 13. Zinc fingers C2HC-type(ZC2HC) & $\mathrm{C}-\mathrm{x}-\mathrm{C}-\mathrm{x}-\mathrm{H}-\mathrm{x}-\mathrm{C}$ & IKBKG,L3MBTL1,ZNF746 \\
\hline 14. GATA zinc-finger-domain containing (GATAD) & $\mathrm{C}-\mathrm{x}-\mathrm{C}-\mathrm{x}-\mathrm{C}-\mathrm{x}-\mathrm{C}$ & GATA4,GATA6,MTA1 \\
\hline 15. ZF class homeoboxes and pseudogenes & $\mathrm{C}-\mathrm{x}-\mathrm{C}-\mathrm{x}-\mathrm{H}-\mathrm{x}-\mathrm{H}$ & 10ADNP,ZEB1,ZHX1 \\
\hline 16. THAP domain containing(THAP) & $\mathrm{C}-\mathrm{x}-\mathrm{C}-\mathrm{x}-\mathrm{C}-\mathrm{x}-\mathrm{H}$ & THAP1,THAP4,THAP11 \\
\hline 17. Zinc fingers CXXC-type(CXXC) & $C-x-C-x-C-x-C-x x x-C-x-C-x-C-x-C$ & CXXC1,CXXC5,MBD1,DNMT1 \\
\hline 18. Zinc fingers SWIM-type(ZSWIM) & $\mathrm{C}-\mathrm{x}-\mathrm{C}-\mathrm{x}-\mathrm{C}-\mathrm{x}-\mathrm{H}$ & MAP3K1,ZSWIM5,ZSWIM6 \\
\hline 19. Zinc fingers AN1-type(ZFAND) & C-x-C-x-C-x-C-xxx-C-x-H-x-H-x-C & ZFAND3,ZFAND6,IGHMBP2 \\
\hline 20. Zinc fingers 3CxxC-type(Z3CXXC) & $\mathrm{C}-\mathrm{x}-\mathrm{C}-\mathrm{x}-\mathrm{H}-\mathrm{x}-\mathrm{C}$ & ZAR1,RTP1,RTP4 \\
\hline 21. Zinc fingers CW-type(ZCW) & $C-x-C-x-C-x-C$ & MORC1,ZCWPW1,KDM1B \\
\hline 22. Zinc fingers GRF-type(ZGRF) & $C-x-C-x-C-x-C$ & TTF2,NEIL3,TOP3A \\
\hline 23. Zinc fingers MIZ-type(ZMIZ) & $\mathrm{C}-\mathrm{x}-\mathrm{C}-\mathrm{x}-\mathrm{H}-\mathrm{x}-\mathrm{C}$ & PIAS1,PIAS3,PIAS4 \\
\hline 24. Zinc fingers BED-type(ZBED) & $\mathrm{C}-\mathrm{x}-\mathrm{C}-\mathrm{x}-\mathrm{H}-\mathrm{x}-\mathrm{H}$ & ZBED1,ZBED4,ZBED6 \\
\hline 25. Zinc fingers HIT-type(ZNHIT) & C-x-C-x-C-x-C-xxx-C-x-C-x-H-x-C & ZNHIT3,DDX59,INO80B \\
\hline 26. Zinc fingers $\mathrm{C} 2 \mathrm{H} 2 \mathrm{C}$-type & $\mathrm{C}-\mathrm{x}-\mathrm{C}-\mathrm{x}-\mathrm{H}-\mathrm{x}-\mathrm{H}$ & MYT1, MYT1L, ST18 \\
\hline 27. Zinc fingers DBF-type(ZDBF) & $\mathrm{C}-\mathrm{x}-\mathrm{C}-\mathrm{x}-\mathrm{H}-\mathrm{x}-\mathrm{H}$ & DBF4, DBF4B, ZDBF2 \\
\hline 28. Zinc fingers MYM-type (ZMYM) & $\mathrm{C}-\mathrm{x}-\mathrm{C}-\mathrm{x}-\mathrm{C}-\mathrm{x}-\mathrm{C}$ & ZMYM2, ZMYM3, ZMYM4 \\
\hline 29. Zinc fingers matrin-type (ZMAT) & $\mathrm{C}-\mathrm{x}-\mathrm{C}-\mathrm{x}-\mathrm{H}-\mathrm{x}-\mathrm{H}$ & ZNF638, ZMAT1, ZMAT3, ZMAT5 \\
\hline 30. Zinc fingers PARP-type & C-x-C-x-H-x-C & PARP1 \\
\hline
\end{tabular}


coordinated immune responses both at the level of transcript as well as post transcriptional level.

\section{Zinc finger proteins: transcriptional regulation of immune response}

Many of the known zinc finger proteins have an important transcriptional role to play in the regulation of immune response.

B lymphocyte-induced maturation protein 1((Blimp-1) Although the differentiation of B cell into immunoglobulin secreting cell is one of the important process in biology yet the complete understanding of overall changes in gene expression is relatively poor. One of the zinc finger protein named B lymphocyte-induced maturation protein 1 (Blimp1 ) is involved in regulating the terminal differentiation of $B$ lymphocytic cells to antibody secreting plasma cells [7]. It is basically a DNA binding zinc finger protein having a $\mathrm{C} 2 \mathrm{H} 2$ type zinc finger consensus. Blimp-1 was first of all cloned from the B cell lymphoma-1 (BCL1) cells from murine upon differentiation to plasma cell state [8] and its enforced expression in mouse spleenocytes or (BCL1) cells helps to convert the B cells to antibody producing plasma B cell primarily by quenching gene expression in mature $\mathrm{B}$ cell and by termination of cell cycle in mature B cells. Blimp-1 represses many important genes encoding transcription factors, like the two recently discovered targets (Id3 and Spi-B) involved in regulating signaling by B cell receptor) and PAX5, c-myc, PAX5.
Further, Blimp-1 down regulates several transcription factor genes (like E2A, EBF etc.) essential for development and function of B cell. Primarily, Blimp-1 functions as a transcriptional repressor causing differentiation of B cells into plasma cells typified by secretion of antibody $\mathrm{M}$, termination of cell division and syndecan-1(a proteoglycan) expression on the cell surface $[9,10]$. The mechanism of action of Blimp-1 is outlined in Fig. 1.

Early B-cell factors (EBF) Another protein with its role in B lymphopoiesis and mature B cell function termed as the early B-cell factors (EBF) is a member of an evolutionary conserved transcription factors having an atypical helixloop-helix motif and zinc finger. The EBF1 protein is characterised by the presence of an N-terminal atypical zinc finger motif (known as "zinc knuckle"with DNA-binding activity important for transcriptional activation of some of the important target genes [11-13]. This transcription factor EBF1 is important in early B cell development primarily for lineage specification. It controls important functions like the development of progenitor-B cell followed by its commitment, and then finally its transformation to the pre-B cell stage. Once activated, EBF1 acts upon its wide range of targets which expresses to form various signaling molecules like $\operatorname{Ig} \beta, \operatorname{Ig} \alpha$, VpreB1/2 and surrogate light chains $\lambda 5$, and all are needed in B-cell development [14]. Infact, the role of this zinc finger protein in B lymphocyte generation is intertwined with other important zinc finger proteins Blimp-1 and zinc finger protein 521 (ZNF521).EBF1 regulates the
Fig. 1 Involvement of Blimp-1 in regulating terminal differentiation of B cells to antibody secreting plasma cell. Blimp-1 represses transcription factors Id3,Spi-B,PAX5, c-myc,CIITA. Blimp-1 causes differentiation of B cells into plasma cells typified by secretion of antibody M, termination 12 of cell division and syndecan-1(a proteoglycan) expression on the cell surface by functioning as a transcriptional repressor

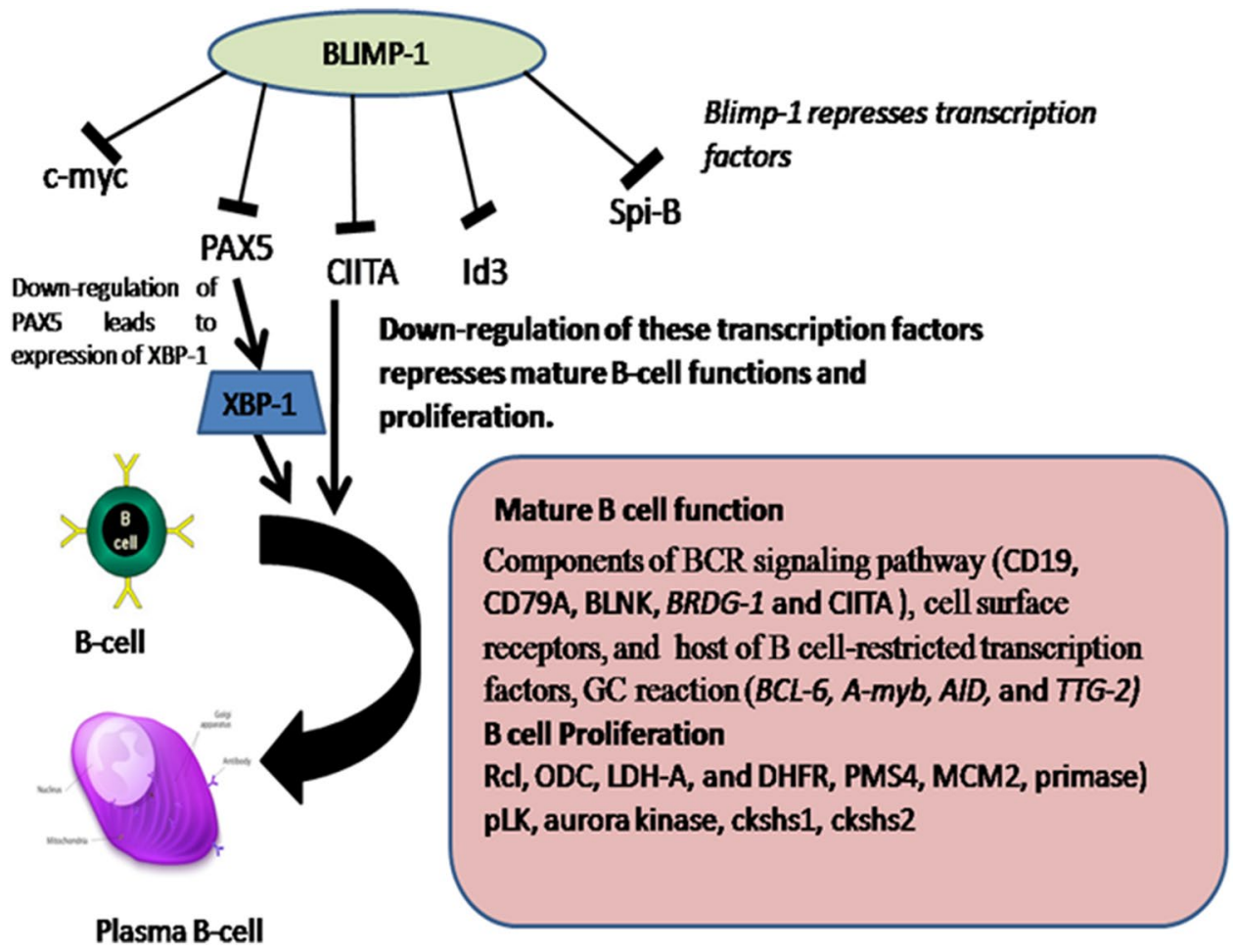


activity of Blimp-1 functioning as a transcriptional repressor for primary effector of immune response and maturation of lymphocyte lineage. ZNF521 plays a role in B cell development by inhibiting EBF1 and therefore influences expression of B cell maturation [15]. The involvement of EBF-1 in B-lymphocyte development is outlined in Fig. 2.

Leukemia/lymphoma-related factor (LRF) Another finger protein named as leukemia/lymphoma-related factor (LRF), which forms dimer in the B lymphocyte nucleus is known to regulate humoral immune response and fate of mature $B$ cell [16].

Zbtb1 (zinc finger and BTB domain containing 1), also known as BTB-ZF The transcriptional regulators involved in development of lymphocytes are of special interest in the field of biology and research with many of them playing a vital role in lymphoid tumorigeneis [17, 18]and some of them involved in directing reprogramming of cell fate [19]. One of the most important transcriptional regulator Zbtb1 (zinc finger and BTB domain containing 1), also known as BTB-ZF (Broad com-plex, Tramtrack, and Bric à brac-zinc finger) influences different processes in immune system like the development of lymphocytes from common lymphoid progenitor (CLP) [20], T lymphocyte versus B lymphocyte development [21], T-helper cell versus Tcytotoxic cell selection [22] and also the development of Natural killer T cell lineage [23]. There are around 49 Zbtb gene family members in mammals containing multiple $\mathrm{C} 2 \mathrm{H} 2$ zinc finger domains, with two Cys and two His residues in a C-2-C-12-H-3-H sequence in canonical form. $\mathrm{Zn}$ atom stabilizes 12 central residues in the Zbtb forming a projection which interacts with the major groove in a double stranded helix [24]. Examples of proteins belonging

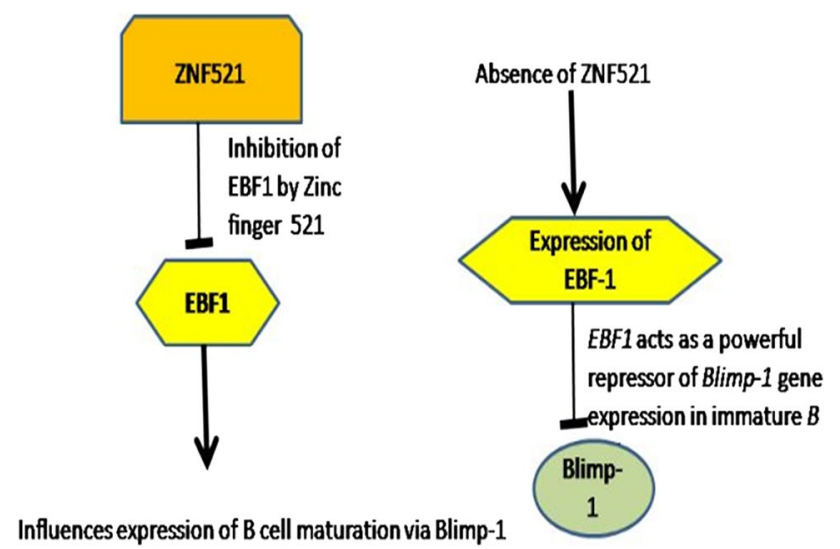

Fig. 2 Involvement of EBF-1 in B cell development. EBF1 regulates the activity of Blimp- functioning as a transcriptional repressor for primary effector of immune response and maturation of lymphocyte lineage. ZNF521 plays a role in B cell development by inhibiting EBF1 and therefore influences expression of B cell to Zbtb family include Th-POK/ZFP67, PLZP, BCL6/ZNF51 and PLZF/Zbtb16 etc. ZBTB1, like many of the other proteins belonging to Zbtb family act as potential transcriptional repressor, function as switches at branch points in different development pathways of human immune system [25], 26 analyzed the transcriptional activity of truncated Zbtb1 proteins containing either a BTB or ZNF functional domain, and concluded that the ZNF domain exhibited strongest repressive activity.

Kruppel-associated box domain (KRAB-ZFPs) One of the important Zinc finger protein Kruppel-associated box domain (KRAB-ZFPs) is a member of one the largest transcriptional regulators family. These proteins are characterized by the presence of KRAB domain localized at the amino terminus and an array of zinc fingers present at the carboxyl terminus which binds DNA. KAP1 (also known as TRIM28) is a co-factor which helps these proteins in regulating different processes at transcriptional level. One of the important role played by these zinc finger proteins (KRAB-ZFPs) is in adaptive immune system where they are involved in the control of viral replication. Both KAP1 and KRAB-ZFP are associated with the repression of Kaposi's sarcoma-associated herpes virus (KSHV). The best characterized example of zinc finger protein is ZNF426 (K-RBP) known to repress transcription of the KSHV transactivator RTA gene known to induce lytic phase from its latent stage and KAP1 which binds and repress several KSHV genes involved in lytic phase[27, 28].

Human immunodeficiency virus (HIV) is also known to be regulated at transcriptional level by zinc finger proteins and two KRAB-ZFPs. HIV infection in macrophages leads to the upregulation of ZNF175 (OTK18) gene which has shown promising results in the regulation of HIV transctiption [29, 30]. Other Zinc finger protein ZBRK1 in combination with KAP1 binds and control expression of HIV promoter [31].

Also another important role played by KRAB-KAP1 complex is in the regulation of $\mathrm{c}-\mathrm{Rel} / \mathrm{NFkB}$ transcription factors which are implicated in the control of interleukins and lineage specific transcription factors. The zinc finger complex negative regulates NFkB transcriptional activity by inhibiting acetylation (through interaction with acetyltransferase $\mathrm{p} 300 / \mathrm{CBP}$ ) of NFkB present at the interleukin6(IL-6) gene [32]. It is important to mention the role of signal transducers and activators of transcription 3(STAT 3 ) which is one of the main activators of cytokine genes for $\mathrm{T}$ lymphocytes and help in driving B cell differentiation. KAP1 primarily exerts its role as transcriptional regulator of NFkB through its interaction with STAT3 [33].

\section{Zinc finger proteins: post transcriptional regulation of immune response}

Though the transcriptional control of immune response is well defined, yet the importance of post transcriptional 
regulation of the immune responses combating infectious microbes is still a matter of enigma. There are various steps of RNA metabolism like capping at 5' end, splicing of introns, addition of poly A tail at 3 'end and degradation where the post transcriptional control can occur. Although, zinc finger proteins are basically the transcription factors which bind DNA, sixty $\mathrm{CCCH}$ zinc finger proteins so far identified in mice and humans function as RNA binding proteins and are implicated in the regulation of RNA metabolism [34]. CCCH zinc finger proteins as the name suggests consist of three cysteines and a histidine residue with one or more characteristic $\mathrm{CCCH}$ zinc finger domain. The functional importance of these Zinc finger proteins (Zfps) has not been extensively elucidated. However, few definitive studies have suggested the role of these in a diverse array of biological immune responses like the production of cytokines, activation of $\mathrm{B}$ and $\mathrm{T}$ cells of immune system, antiviral responses and immune homeostasis to name a few $[35,36]$.

\section{Three Main CCCH protein families}

There are three $\mathrm{CCCH}$ zinc protein families which are evolutionary closely related- tristetraprolin(TTP), roquin 1 and roquin 2 , and monocyte chemotactic protein-induced protein 1 (MCPIP1) or regnase 1, which targets mRNA for degradation and modulate various signalling pathways to control the activation of both adaptive and innate immune responses [34].

TTP

It belongs to Zfp36 gene family and was discovered when fibroblasts were stimulated with mitogens and growth factors $[37,38]$. This protein is known to associate with the AU rich elements(AREs) in mRNA and this increases the likelihood of mRNA degradation by causing the removal of polyadenylated tail(deadenylation) [39]. Besides containing the unique $\mathrm{CCCH}$ zinc finger domains, this protein also contains three proline rich domains, a conserved NOT1 binding domain present at the $\mathrm{C}$ terminus which binds the NOT1 scaffolding protein and nuclear export sequence localized at the amino terminus.

\section{Physiological roles of TTP}

\section{Tumor Necrosis Factor (TNF) production regulation}

The mRNAs encoding cytokine TNF (a mediator of immune and inflammatory responses) are normally subjected to degradation involving the AREs in the $3^{\prime} \mathrm{UTR}$. The TTP is a sine quano element in this regard because of its direct binding to AREs in the $3^{\prime}$-UTR and moreover it also recruits two key complexes (CCR4-CAF1-NOT1 deadenylase and
4EHP-GYF2 cap binding complex) for the destabilization of mRNA by deletion of AREs from the transcript which thereby results in the TNF hypersecretion [40].The experimental evidence for the role of TTP in this aspect came from the studies in which it was shown that the mice lacking TTP developed several pathological conditions like inflammatory arthritis, dermatitis, autoantibodies generation, cachexia and myeloid hyperplasia [41]. Moreover, when such deficient mice were treated with either antibody specific for TNF or crossed with mice deficient in TNF receptor 1 , the occurrence of above pathological states could be mitigated.

\section{Interleukin 6(IL-6, Aproinflammatory cytokine) production regulation}

The IL-6 transcript is unique because of the presence of five ARE in the 3'-UTR and can promote the destabilization of mRNA by binding to ARE2, ARE3 and ARE4. A study conducted by [42]showed that the mice deficient in TTP and injected with IL-1 $\beta$ depicted marked elevation in IL- 6 production which therefore opines that TTP is involved in the direct regulation of IL-6.

\section{Interleukin 10(IL-10)production regulation}

It acts as an inhibitor of inflammation through the suppression of pro-inflammatory cytokine production by macrophages. As with other cytokines, TTP was known to mediate mRNA degradation by direct binding to ARE in the 3'-UTR [43]. Moreover, IL-10 induced TTP expression in macrophages through activation of STAT3 (activator and signal transducer of transcription) which therefore conjectures the negative feedback loop controlling IL-10 cytokine production[44]

\section{Roquin}

It was discovered as a product of the mutation taking place in the Roquin gene locus [45]. This is unique because it is known to have ROQ domain ( 300 amino acids) through which it recognizes the stem loop motifs present in the 3'UTR of its target mRNA.It promotes the degradation of mRNA by interacting with an additional enhancer protein like EDC4 (decapping protein) and RCK(helicase protein) $[46,47]$.

\section{Physiological roles of roquin 1}

\section{TNF production regulation}

This protein mediates TNF mRNA degradation by binding to the Constitutive Decay Element(CDE) present downstream to the ARE in the 3'-UTR through its ROQ domain and also 
recruits $\mathrm{RCK}$ (a helicase) and EDC4 (decapping enzyme) [48]. It is noteworthy here that both TTP and Roquin CCCH zinc finger proteins are involved in the TNF production regulation as is evident from an in vivo study in which Roquin $1 \mathrm{san} / \mathrm{san}$ mice developed pathological conditions of inflammation and arthritis just like mice deficient in TTP [49]. As reports are coming from across the global scientific community that insurmountable levels of TNF are associated with development of an inflammatory response in the lungs of patients affected with COVID-19 [50], the complex TTP and Roquin pathways might be the novel drug targets for the treatment of corona pandemic along with other inflammatory diseases.

\section{MCPIP1, MCPIP2, MCPIP3 and MCPIP4}

These contain RNase domain rich in Serine residues at the carboxyl terminus, an ubiquitin associated domain at the amino terminus besides containing the $\mathrm{CCCH}$ zinc finger domain [51]. These are known to mediate the decay of mRNA by the binding of RNase domain to the target mRNA where it depicts an intrinsic ribonuclease action.

\section{Physiological roles of MCPIP1}

\section{IL-6 production regulation}

It is a key regulator for the production of IL-6 by macrophages and mediates this action by binding and cleaving a conserved stem loop element present in the transcript of IL-6 at the 3'-UTR through its endonuclease activity aided by a helicase (UPF1) [51, 52]. This finding was supported by the fact that the mice lacking MCPIP1 depicted higher IL-6 levels as compared to normal mice since its mRNA was found to be more stable in MCPIP1 deficient macrophages compared with the normal wild type macrophages [51]. MCPIP1 and Roquin CCCH Zinc finger proteins are known to cause degradation of mRNAs at different phases of immune response, with MCPIP1 controlling the early phase and degrading active mRNA whereas Roquin 1 controlled the later phase of inflammation by degradation of an inactive mRNA.These findings corroborate the fact that the three $\mathrm{CCCH}$ zinc finger proteins (TTP, MCPIP1 and Roquin 1) involve a complex interplay to coordinate the pro-inflammatory and anti- inflammatory cytokine expression in order to generate an efficient and timely immune response.

Apart from the physiological roles of Roquin, TTP and MCPIP1 discussed above, the $\mathrm{CCCH}$ zinc finger proteins have a role in macrophage activation, $\mathrm{T}$ cell Activation etc.

\section{Role of CCCH zinc finger proteins in macrophage activation}

The $\mathrm{CCCH}$ zinc finger proteins are known to control macrophage activation at the level of post transcription by causing the degradation of the inflammatory cytokines (TNF, IL-6, IL-10 etc.) mRNA or causing attenuation of the RNA synthesis through inhibition of the various signal transduction pathways that activate their expression. Basically, macrophages are known to express pattern recognition receptors (PRRs) which are important for the activation of various transcription factors like AP- 1 and NF- $\mathrm{\kappa B}$ and therefore this leads to the cytokine expression involved in the immune activation [34]. TLR ligands like Lipopolysaccharide (LPS) and various pro-inflammatory cytokines like IL-1 $\beta$, TNF induces the expression of MCPIP1 mRNA which in turn negatively regulate the activation of macrophages through various mechanisms. To exemplify, this involves the ribonuclease activity of MCPIP1 in order to induce the degradation of pro-inflammatory cytokines (IL-12, IL-6, IL-1 $\beta$ ) mRNA [53]. In addition to this, MCPIP1 might act as an adaptor molecule involved in the formation of a complex with other proteins like USP10 and TANK to inhibit transcription factors like NF- $\mathrm{\kappa B}$ and JNK (mitogen activated protein kinase) by promoting the deubiquitylation of TNF receptor associated factor 3 and factor 6 [54-56]. TTP was shown to negatively regulate the NF- $\mathrm{\kappa Bsignalling}$ by functioning as a co-repressor or by interfering with the translocation of p65 in the nucleus [57-59]. The experimental evidence for the TTP and MCPIP1 mediating their effects through the same pathway came from the mice models lacking TTP and MCPIP1 which were shown to be highly sensitive to LPS induced septic shock due to elevated TNF levels [60, 61].

Although Regnase and TTP was shown to negatively regulate NF- $\kappa$ Bsignalling, Roquin was known to promote the activity of the NF- $\kappa B$ kinase inhibitor (IKK). This is accomplished by causing degradation of an Ubiquitin editing enzyme (A20) mRNA through its $\mathrm{CCCH}$ zinc finger and ROQ domains which interact with a stem loop structure present downstream to the ARE in the 3'-UTR [62].

\section{Role of CCCH zinc finger proteins in T cell activation}

In the $\mathrm{T}$ cells, the $\mathrm{CCCH}$ zinc finger proteins are highly expressed [51]. MCPIP1 is of paramount importance in preventing the autoantibodies generation in a process known as autoimmunity. The negative regulation of $\mathrm{T}$ cell activation involves the degradation of mRNA expressing various immuno-regulatory molecules like REL which is normally associated with the TH1 cell activation for the generation of auto-immune disorders [63]. The functional validation for this role was confirmed by studies in mouse models deficient in MCPIP1, where the loss of REL inhibited the generation 
of the auto-immunity which thereby authenticates that the increased REL expression because of defect in mRNA decay contributes to T cell activation [64].

Besides the destabilization of mRNA, splicing of mRNA to remove introns is also vital to negatively regulate $\mathrm{T}$ cell activation. CD45 (a tyrosine phosphatase) removes inhibitory phosphate from various kinases like LCK and SRC and is involved in the $\mathrm{T}$ cell activation [65]. The $\mathrm{CCCH}$ zinc finger protein $\mathrm{U} 2 \mathrm{AF} 26$ cooperates with GF11 to cause CD45 splicing which results in the formation of CD45RO isoform that is transcriptionally less active [66].

That being said, these studies reiterate the fact that post transcriptional events especially mRNA decay is vital to suppress the aberrant activation of both the adaptive and innate immune responses.

\section{Conclusion}

It is reasonable to conclude that zinc finger proteins have an important role to play in the regulation of immune responses at transcriptional and post transcriptional levels. Insights into these pathway and mechanism of regulation by zinc finger proteins might provide clues for targets implicated in the treatment of various inflammatory and autoimmune diseases.

Author contributions GS contributed in conceptualization and drawing of hypothesis for the study along with contribution in manuscript writing. GR contributed substantially in study design, manuscript writing, editing.

Funding Not applicable.

\section{Declarations}

Conflict of interest The authors do not have any financial or non-financial conflict of interest.

Informed consent All the authors declare their consent for publication.

\section{References}

1. FAO/WHO (2004) Expert consultation on human vitamin and mineral requirements, vitamin and mineral requirements in human nutrition: report of joint FAO/WHO expert consolation, 2nd edition, Bangkok, Thailand, pp 341

2. Klug A, Rhodes D (1987) Zinc fingers: a novel protein fold for nucleic acid recognition. Cold Spring Harb Symp Quant Biol $52: 473-482$

3. Solomons NW (2013) Update on zinc biology. Ann Nutr Metab 62:8-17
4. Finerty PJ Jr, Bass BL (1999) Subsets of the zinc finger motifs in dsRBP-ZFa can bind double-stranded RNA. Biochemistry 38:4001-4007

5. Gaullier JM, Simonsen A, D'Arrigo A, Bremnes B, Stenmark H, Aasland R (1998) FYVE fingers bind PtdIns(3)P. Nature 394:432-433

6. Mackay JP, Crossley M (1998) Zinc fingers are sticking together. Trends Biochem Sci 23:1-4

7. John SA, Garrett-Sinha LA (2009) Blimp1: a conserved transcriptional repressor critical for differentiation of many tissues. Exp Cell Res 315:1077-1084

8. Turner CA Jr, Mack DH, Davis MM (1994) Blimp-1, a novel zinc finger-containing protein that can drive the maturation of B lymphocytes into immunoglobulin-secreting cells. Cell 77:297-306

9. Angelin-Duclos C, Cattoretti G, Chang D, Lin K, Lin Y, Yu J, Calame K (1999) The role of B lymphocyte induced maturation protein-1 (BLIMP-1) in terminal differentiation of B cells and other cell lineages. Cold Spring Harbor Symp Quant Biol 64:61-70

10. Minnich M, Tagoh H, Bönelt P, Axelsson E, Fischer M, Cebolla $B$ et al (2016) Multifunctional role of the transcription factor Blimp-1 in coordinating plasma cell differentiation. Nat Immunol 17:331-343

11. Hagman J, Gutch MJ, Lin H, Grosschedl R (1995) EBF contains a novel zinc coordination motif and multiple dimerization and transcriptional activation domains. EMBO J 14:2907-2916

12. Travis A, Hagman J, Hwang L, Grosschedl R (1993) Purification of early-B-cell factor and characterization of its DNA-binding specificity. Mol Cell Biol 13:3392-3400

13. Fields S, Ternyak K, Gao H, Ostraat R, Akerlund J, Hagman J (2008) The 'zinc knuckle' motif of early B cell factor is required for transcriptional activation of B cell-specific genes. Mol Immunol 45:3786-3796

14. Treiber T, Mandel EM, Pott S, Györy I, Firner S, Liu ET, Grosschedl R (2010) Early B cell factor 1 regulates B cell gene networks by activation, repression, and transcription- independent poising of chromatin. Immunity 32:714-725

15. Mega T, Lupia M, Amodio N, Horton SJ, Mesuraca M, Pelaggi $\mathrm{D}$ et al (2011) Zinc finger protein 521 antagonizes early B-cell factor 1 and modulates the B-lymphoid differentiation of primary hematopoietic progenitors. Cell Cycle 10:2129-2139

16. Lee SU, Maeda T (2012) POK/ZBTB proteins: an emerging family of proteins that regulate lymphoid development and function. Immunol Rev 247:107-119

17. Mullighan CG, Goorha S, Radtke I, Miller CB, Coustan-Smith E, Dalton JD et al (2007) Genome-wide analysis of genetic alterations in acute lymphoblastic leu-kaemia. Nature 446:758-764

18. Mullighan CG, Miller CB, Radtke I, Phillips LA, Dalton J, Ma J (2008) BCR-ABL1 lymphoblastic leukaemia is characterized by the deletion of Ikaros. Nature 453:110-114

19. Cobaleda C, Jochum W, Busslinger M (2007) Conversion of mature $\mathrm{B}$ cells into $\mathrm{T}$ cells by dedifferentiation to uncommitted progenitors. Nature 449:473-477

20. Kosan C, Saba I, Godmann M, Herold S, Herkert B, Eilers M, Möröy T (2010) Transcription factor miz-1 is required to regulate inter-leukin-7 receptor signaling at early commitment stages of $\mathrm{B}$ cell differentiation. Immunity 33:917-928

21. Maeda T, Merghoub T, Hobbs RM, Dong L, Maeda M, Zakrzewski J et al (2007) Regulation of B versus T lymphoid lineage fate decision by the proto-oncogene LRF. Science 316:860-866

22. He X, He X, Dave VP, Zhang Y, Hua X, Nicolas E, Xu W, Roe BA, Kappes DJ (2005) The zinc finger transcription factor ThPOK regulates CD4 versus CD8 T-cell lineage commitment. Nature 433:826-833

23. Kovalovsky D, Uche OU, Eladad S, Hobbs RM, Yi W, Alonzo E et al (2008) The BTB-zinc finger transcriptional regulator 
PLZF controls the development of invari-ant natural killer T cell effector functions. Nat Immunol 9:1055-1064

24. Evans RM, Hollenberg SM (1988) Zinc fingers: gilt by association. Cell 52:1-3

25. Punwani D, Simon K, Choi Y, Dutra A, Gonzalez-Espinosa D, Paket E et al (2012) Transcription factor zinc finger and BTB domain 1 is essential for lymphocyte development. J Immunol 189:1253-1264

26. Liu Q, Yao F, Wang M, Zhou B, Cheng H, Wang W, Jin L, Lin Q, Wang JC (2011) Novel human BTB/POZ domain-containing zinc finger protein $\mathrm{ZBTB} 1$ inhibits transcriptional activities of CRE. Mol Cell Biochem 357:405-414

27. Chang PC, Fitzgerald LD, Van Geelen A, Izumiya Y, Ellison TJ, Wang DH et al (2009) Kruppel-associated box domain-associated protein-1 as a latency regulator for Kaposi's sarcomaassociated herpesvirus and its modulation by the viral protein kinase. Cancer Res 69:5681-5689

28. Yang Z, Wen H-J, Minhas V, Wood C (2009) The zinc finger DNA-binding domain of K-RBP plays an important role in regulating Kaposi's sarcoma-associated herpesvirus RTA-mediated gene expression. Virology 391:221-231

29. Carlson KA, Leisman G, Limoges J, Pohlman GD, Horiba M, Buescher J, Gendelman HE, Ikezu T (2004) Molecular characterization of a putative antiretroviral transcriptional factor, OTK18. J Immunol 172:381-391

30. Horiba M, Martinez LB, Buescher JL, Sato S, Limoges J, Jiang Y, Jones C, Ikezu T (2007) OTK18, a zinc-finger protein, regulates human immunodeficiency virus type 1 long terminal repeat through two distinct regulatory regions. J Gen Virol 88:236-241

31. Nishitsuji H, Abe M, Sawada R, Takaku H (2012) ZBRK1 represses HIV-1 LTR-mediated transcription. FEBS Lett 586:3562-3568

32. Kamitani S, Togi S, Ikeda O, Nakasuji M, Sakauchi A, Sekine Y et al (2011) Krüppel-associated box-associated protein 1 negatively regulates TNF- $\alpha$-induced NF- $\kappa \mathrm{B}$ transcriptional activity by influencing the interactions among STAT3, p300, and NF-кB/p65. J Immunol 187:2476-2483

33. Tsuruma R, Ohbayashi N, Kamitani S, Ikeda O, Sato N, Muromoto R et al (2008) Physical and functional interactions between STAT3 and KAP1. Oncogene 27:3054-3059

34. Fu M, Blackshear PJ (2017) RNA-binding proteins in immune regulation: a focus on $\mathrm{CCCHzinc}$ finger proteins. Nat Rev Immunol 17:130-143

35. Carpenter S, Ricci EP, Mercier BC, Moore MJ, Fitzgerald KA (2014) Post-transcriptional regulation of gene expression in innate immunity. Nat Rev Immunol 14:361-376

36. Man K, Kallies A (2015) Synchronizing transcriptional control of $\mathrm{T}$ cell metabolism and function. Nat Rev Immunol $15: 574-584$

37. Lai WS, Stumpo DJ, Blackshear PJ (1990) Rapid insulin-stimulated accumulation of an mRNA encoding a proline-rich protein. J Biol Chem 265:16556-16563

38. Gingerich TJ, Stumpo DJ, Lai WS, Randall TA, Steppan SJ, Blackshear PJ (2016) Emergence and evolution of Zfp3613. Mol Phylogenet Evol 94:518-530

39. Lai WS, Carballo E, Thorn JM, Kennington EA, Blackshear PJ (2000) Interactions of $\mathrm{CCCH}$ zinc finger proteins with mRNA: binding of tristetraprolin-related zinc finger proteins to $\mathrm{AU}$ rich elements and destabilization of mRNA. J Biol Chem 275:17827-17837

40. Vinuesa CG, Cook MC, Angelucci C, Athanasopoulos V, Rui L, Hill KM et al (2005) A RING- type ubiquitin ligase family member required to repress follicular helper T cells and autoimmunity. Nature 435:452-458

41. Glasmacher E, Hoefig KP, Vogel KU, Rath N, Du L, Wolf C et al (2010) Roquin binds inducible costimulator mRNA and effectors of mRNA decay to induce microRNA-independent post-transcriptional repression. Nat Immunol 11:725-733

42. Maeda K, Akira S (2017) Regulation of mRNA stability by $\mathrm{CCCH}$-type zinc-finger proteins in immune cells. Int Immunol 29:149-155

43. Matsushita K, Takeuchi O, Standley DM, Kumagai Y, Kawagoe T, Miyake T et al (2009) Zc3h12a is an RNase essential for controlling immune responses by regulating mRNA decay. Nature 458:1185-1190

44. Mino T, Takeuchi O (2018) Post-transcriptional regulation of immune responses by RNA binding proteins. Proc Jpn Acad Ser B Phys Biol Sci 94:248-258

45. Taylor GA, Carballo E, Lee DM, Lai WS, Thompson MJ, Patel DD et al (1996) A pathogenetic role for TNF $\alpha$ in the syndrome of cachexia, arthritis, and autoimmunity resulting from tristetraprolin (TTP) deficiency. Immunity 4:445-454

46. Zhao W, Liu M, D'Silva NJ, Kirkwood KL (2011) Tristetraprolin regulates interleukin-6 expression through p38 MAPK-dependent affinity changes with mRNA 3 ' untranslated region. J Interferon Cytokine Res 31:629-637

47. Stoecklin G, Tenenbaum SA, Mayo T, Chittur SV, George $\mathrm{AD}$, Baroni TE et al (2008) Genome-wide analysis identifies interleukin-10 mRNA as target of tristetraprolin. J Biol Chem 283:11689-11699

48. Gaba A, Tenenbaum SA, Mayo T, Chittur SV, George AD, Baroni TE et al (2012) Cutting edge: IL-10-mediated tristetraprolin induction is part of a feedback loop that controls macrophage STAT3 activation and cytokine production. J Immunol 189:2089-2093

49. Leppek K, Schott J, Reitter S, Poetz F, Hammond MC, Stoecklin G (2013) Roquin promotes constitutive mRNA decay via a conserved class of stem-loop recognition motifs. Cell 153:869-881

50. Pratama A, Ramiscal RR, Silva DG, Das SK, Athanasopoulos V, Fitch J et al (2013) Roquin-2 shares functions with its paralog Roquin-1 in the repression of mRNAs controlling $\mathrm{T}$ follicular helper cells and systemic inflammation. Immunity 38:669-680

51. Di R, Gualtieri L, Pivari P (2020) COVID-19: Is there a role for immunonutrition in obese patient? J Trans1 Med 18:415

52. Mino T, Murakawa Y, Fukao A, Vandenbon A, Wessels HH, Ori D et al (2015) Regnase-1 and Roquin regulate a common element in inflammatory mRNAs by spatiotemporally distinct mechanisms. Cell 161:1058-1073

53. Mizgalska D, Wegrzyn P, Murzyn K, Kasza A, Koj A, Jura J et al (2009) Interleukin-1-inducible MCPIP protein has structural and functional properties of RNase and participates in degradation of IL-1 $\beta$ mRNA. FEBS J 276:7386-7399

54. Liang J, Saad Y, Lei T, Wang J, Qi D, Yang Q et al (2010) MCPinduced protein 1 deubiquitinates TRAF proteins and negatively regulates JNK and NF- $\mathrm{KB}$ signaling. J Exp Med 207:2959-2973

55. Niu J, Shi Y, Xue J, Miao R, Huang S, Wang T et al (2013) USP10 inhibits genotoxic NF- $\mathrm{KB}$ activation by MCPIP1-facilitated deubiquitination of NEMO. EMBO J 32:3206-3219

56. Wang W, Huang X, Xin HB, Fu M, Xue A, Wu ZH (2015) TRAF family member-associated NF- $\mathrm{kB}$ activator (TANK) inhibits genotoxic nuclear factor $\kappa \mathrm{B}$ activation by facilitating deubiquitinase USP10-dependent deubiquitination of TRAF6 ligase. J Biol Chem 290:13372-13385

57. Liang J, Lei T, Song Y, Yanes N, Qi Y, Fu M (2009) RNA-destabilizing factor tristetraprolin negatively regulates NF- $\kappa \mathrm{B}$ signaling. J Biol Chem 284:29383-29390

58. Schichl YM, Resch U, Hofer-Warbinek R, de Martin R (2009) Tristetraprolin impairs NF- $\mathrm{kB} / \mathrm{p} 65$ nuclear translocation. J Biol Chem 284:29571

59. Gu L, Ning H, Qian X, Huang Q, Hou R, Almourani R et al (2013) Suppression of IL-12 production by tristetraprolin through blocking NF-кB nuclear translocation. J Immunol 191:3922-3930 
60. Qiu LQ, Stumpo DJ, Blackshear PJ (2012) Myeloid-specific tristetraprolin deficiency in mice results in extreme lipopolysaccharide sensitivity in an otherwise minimal phenotype. J Immunol 188:5150-5159

61. Huang S, Miao R, Zhou Z, Wang T, Liu J, Liu G et al (2013) MCPIP1 negatively regulates Toll-like receptor 4 signaling and protects mice from LPS-induced septic shock. Cell Signal 25:1228-1234

62. Song HY, Rothe M, Goeddel DV (1996) The tumor necrosis factor-inducible zinc finger protein A20 interacts with TRAF1/ TRAF2 and inhibits NF- $\kappa$ B activation. Proc Natl Acad Sci USA 93:6721-6725

63. Hilliard BA, Mason N, Xu L, Sun J, Lamhamedi-Cherradi SE, Liou HC et al (2002) Critical roles of c-Rel in autoimmune inflammation and helper T cell differentiation. J Clin Invest 110:843-850
64. Uehata T, Iwasaki H, Vandenbon A, Matsushita K, HernandezCuellar E, Kuniyoshi K et al (2013) Malt1-induced cleavage of regnase-1 in CD4+ helper $\mathrm{T}$ cells regulates immune activation. Cell 153:1036-1049

65. Mustelin T, Tasken K (2003) Positive and negative regulation of $\mathrm{T}$-cell activation through kinases and phosphatases. Biochem $\mathbf{J}$ 371:15-27

66. Heyd F, ten Dam G, Möröy T (2006) Auxiliary splice factor U2AF26 and transcription factor Gfi1 cooperate directly in regulating CD45 alternative splicing. Nat Immunol 7:859-867

Publisher's Note Springer Nature remains neutral with regard to jurisdictional claims in published maps and institutional affiliations. 